\title{
Prevalence of mild hyponatremia and its association with falls in older adults admitted to an emergency geriatric medicine unit (the MUPA unit)
}

Sophie Boyer ${ }^{1,2}$, Caroline Gayot ${ }^{2,3}$, Charlotte Bimou', Thomas Mergans ${ }^{3,4}$, Patrick Kajeu ${ }^{2,4}$, Muriel Castelli ${ }^{2,4}$, Thierry Dantoine ${ }^{1}$ and Achille Tchalla, ${ }^{1,2,3,4,5^{*}}$ (1)

\begin{abstract}
Background: Hyponatremia is the most common electrolyte disorder in older adults and it can increase morbidity and mortality. Approximately one in three older adults fall each year; mild chronic hyponatremia can predispose this group to injurious falls and fractures and serum levels of sodium can also influence bone health. Little is known regarding the association between mild chronic hyponatremia and injurious fall prevalence in elderly patients admitted to the Emergency Department (ED). Therefore, the present study investigated the link between mild hyponatremia and the risk of injurious falls in elderly patients admitted to the Emergency Geriatric Medicine Unit (The MUPA Unit).

Methods: This cross-sectional study was conducted over 4 months and included patients $\geq 75$ years of age who were admitted to the MUPA Unit of University Hospital Center of Limoges (France). Sociodemographic factors, fall events, comorbidities, medications, and sodium levels were assessed (hyponatremia was considered as sodium level $<136 \mathrm{mEq} / \mathrm{L}$ ). Additionally, the short Comprehensive Geriatric Assessment (short-CGA), the Frailty score on the Short Emergency Geriatric Assessment (SEGA), and the Katz Activity of Daily Living (ADL) scale were administered.

Results: Of the 696 cases included in the final analysis, the mean age was $86.1 \pm 5.6$ years and $63.1 \%$ were female. The prevalence of falls was 27.9\% (95\% confidence interval [CI]: 24.6-31.2\%) and that of mild hyponatremia was 15.9\% (95\% Cl: 13.2-18.6\%). The prevalence rate of mild hyponatremia was 13.2\% (95\% Cl: 10.1-16.3\%) in patients without falls and $26.1 \%$ (95\% Cl: 19.8-32.4\%) in patients admitted for falls. Mild hyponatremia was significantly associated with falls $(P<0.001)$ and the adjusted odds ratio $(O R)$ was 3.02 (95\% Cl: 1.84-4.96).

Conclusions: Because mild hyponatremia might be a risk factor for injurious falls and ED admission, determination of sodium levels during basic biomarker assessment on ED admission could be an important component of fall prevention strategies for the elderly.
\end{abstract}

Keywords: Mild hyponatremia, Falls, Emergency department, Older adult, Prevalence, Prevention

\footnotetext{
* Correspondence: Achille.tchalla@unilim.fr

${ }^{1}$ EA 6310 HAVAE Handicap Activité Vieillissement Autonomie Environnement, Université de Limoges, F-8705 Limoges, France

${ }^{2}$ Unité de Recherche Clinique et Innovation (URCI) en Gérontologie (Axe Silver économie, e-santé et Télémédecine), Pôle HU Gérontologie Clinique, $\mathrm{CHU}$ de Limoges, 2 Avenue Martin-Luther King, 87042 Limoges, France Full list of author information is available at the end of the article
}

(c) The Author(s). 2019 Open Access This article is distributed under the terms of the Creative Commons Attribution 4.0 International License (http://creativecommons.org/licenses/by/4.0/), which permits unrestricted use, distribution, and reproduction in any medium, provided you give appropriate credit to the original author(s) and the source, provide a link to the Creative Commons license, and indicate if changes were made. The Creative Commons Public Domain Dedication waiver (http://creativecommons.org/publicdomain/zero/1.0/) applies to the data made available in this article, unless otherwise stated. 


\section{Background}

Falls in the elderly is a major public health issue, as post-fall complications are the third leading cause of chronic disability and mortality [1]. Approximately $30 \%$ of community dwelling patients over 65 years of age, and half of patients over 80 years of age, fall at least once per year [2]. Furthermore, approximately $30 \%$ of falls result in moderate or severe injuries [3] and can affect the ability of an individual to engage in activities of daily living [4]. Therefore, falls may be considered as the first step towards dependence because approximately $40 \%$ of elderly people hospitalised for falls are institutionalised [5] and the mortality rate ranges from 7 to $11 \%[3,5]$.

Thus, greater knowledge of risk factors of falls is extremely important for the prevention of accidents and dependence in the elderly. Falls have many risk factors. Internal risk factors include cognitive impairments, effects of medication, and sarcopenia; external risk factors include type of flooring and footwear [6]. Although the biologicals risk factors of falls remain poorly studied, hyponatremia is the most common electrolyte disorder in clinical practice [7]. This electrolyte imbalance is defined as a serum sodium concentration $<136 \mathrm{mEq} / \mathrm{L}$ [8] and can be divided into three stages: mild chronic hyponatremia (serum sodium of $130-135 \mathrm{mEq} /$ )L, moderate hyponatremia (serum sodium levels of $125-129 \mathrm{mEq} / \mathrm{L}$ ), and severe hyponatremia (serum sodium levels $<125$ $\mathrm{mEq} / \mathrm{L}$ [9];). Cross-sectional population studies have shown that the incidence of hyponatremia increases with age [10]. For example, hyponatremia affects approximately $18 \%$ of older people living in the community [7] and nearly $20 \%$ of elderly people who present to the emergency department (ED) [11].

Hyponatremia has many causative factors, especially in older patients with a greater predisposition due to physiological deterioration, comorbidities, and/or polypharmacy $[12,13]$. The clinical symptoms are generally associated with the severity of hyponatremia, with the most frequently encountered symptoms being nausea, fatigue, and headache $[8,14]$. Classically, mild chronic hyponatremia is defined as asymptomatic but it has recently been shown that it could be clinically significant [15], may be associated with the risk of fracture in ambulatory cohorts $[16,17]$, and could result in gait disturbances and impaired cognitive function [18]. Thus, the present study aimed to determine the prevalence of mild chronic hyponatremia, and to examine the relationship between mild chronic hyponatremia and falls, in an Emergency Geriatric Medicine Unit (MUPA Unit). It was hypothesised that mild hyponatremia would be a biological marker for fall risk in an elderly population.

\section{Methods}

\section{Study design and setting}

This study was an observational and cross-sectional investigation of patients $\geq 75$ years of age at baseline, who had been admitted to the MUPA Unit at Limoges University Hospital Center (France) between November 1, 2014 and March 31, 2015. Patients who were living at home and admitted to the MUPA Unit for a non-vital emergency (i.e., not admitted for stroke or to the intensive cardiac unit or palliative unit) were included. The exclusion criteria included the absence of serum sodium measurements. Baseline demographic and clinical data were collected using a comprehensive geriatric assessment (CGA). Data confidentiality was ensured, written informed consent was obtained from each participant and the study protocol was approved by the local ethics committee. The study was conducted according to the principles of the Helsinki Declaration.

\section{Hyponatremia assessment}

Hyponatremia was defined as a serum sodium level < $136 \mathrm{mEq} / \mathrm{L}$, mild chronic hyponatremia as a serum sodium level between 130 and $135 \mathrm{mEq} / \mathrm{L}$, moderate hyponatremia as a sodium level between 125 and $129 \mathrm{mEq} / \mathrm{L}$, and severe hyponatremia as a serum sodium level $<125$ $\mathrm{mEq} / \mathrm{L}$ [9]. Data concerning natremia were obtained from the first blood test performed after the patient arrived at the MUPA Unit.

\section{Fall assessment}

The incidence of falls was determined by reviewing medical records for falls documented either as part of the presenting complaint or during physical examination. A fall was defined as unintentionally coming to rest on the ground or other lower level not as a result of a major intrinsic event (e.g. myocardial infarction, stroke, or seizure) or an overwhelming external hazard (e.g. hit by a vehicle [19, 20];). All patients who reported falls were also asked to give the circumstances of the fall and report clinical outcomes, including whether any injuries (e.g. fractures), ED visits, and/or hospital visits had occurred. An injurious fall was identified using the question: "Did you hurt yourself in any way when you fell?"

\section{Other covariates}

Relevant demographic, clinical, and outcome data were collected by a review of medical records and included the following variables: age; gender; frailty, assessed using the Short Emergency Geriatric Assessment (SEGA) scale [21]; autonomy, assessed using the Activity of Daily Living (ADL) scale [22]; medication adherence, assessed using the Morisky-Green test [23]; emergency frailty score, assessed using the Identification of Senior At Risk (ISAR) scale [24];; depression, assessed using the Geriatric Depression Scale (GDS) [25]; number of diseases; and number of prescription drugs used. All geriatric assessments were administered when the patient arrived at the MUPA Unit. The 
rates of rehospitalisation for falls and mortality at 1 month, 3 months, and 1 year were determined by a review of medical records.

\section{Data collection}

Data were collected at baseline from the medical records of 696 patients who had been admitted to the MUPA Unit at Limoges University Hospital Center (France) between November 1, 2014 and March 31, 2015.

\section{Data analysis}

Descriptive statistics are expressed as means \pm standard error (SE). Student's $t$-tests were used to compare the means of continuous, normally distributed data, to reveal factors associated with mild hyponatremia and falls. Univariate and multivariate analyses were conducted by applying a multiple logistic stepwise regression procedure [26] to obtain variables that were independently correlated with mild hyponatremia. All statistical tests were two-tailed and a significance level of $p \leq 0.05$ was considered to indicate statistical significance. All analyses were performed with $\mathrm{SAS}^{\bullet}$ software (SAS Institute; Cary, NC USA).

\section{Results}

\section{Participant characteristics}

A total of 733 eligible patients were admitted to the MUPA Unit during the study period. Patients admitted to the MUPA Unit for a non-vital emergency (i.e., not for stroke), the intensive cardiac unit, or the palliative unit were included in the present study. Additionally, 37 patients were excluded due to the absence of serum sodium measurements in the first blood test conducted on arrival at the MUPA Unit; thus, a total of 696 patients were included in the final analysis (Fig. 1.)

The general characteristics of the study population are presented in Table 1; the mean age was $86.1 \pm$ 5.6 years and the majority of patients were female $(63.1 \%, n=439)$. The study population was considered to be very frail based on the mean SEGA scale $(13.4 \pm 4)$ and ISAR scale $(3.7 \pm 1.2)$ scores. The mean ADL score was $3.9 \pm 1.9$, the Morisky-Greene test for medication adherence had a mean score of $3.5 \pm 1.2$, and the mean score on the GDS scale was $1.4 \pm 1.4$. Furthermore, the study population was polypathological (number of diseases per patient= $4.3 \pm 2.6$ ) and polymedicated (mean number of drugs used $=6.4 \pm 3.1$ ).

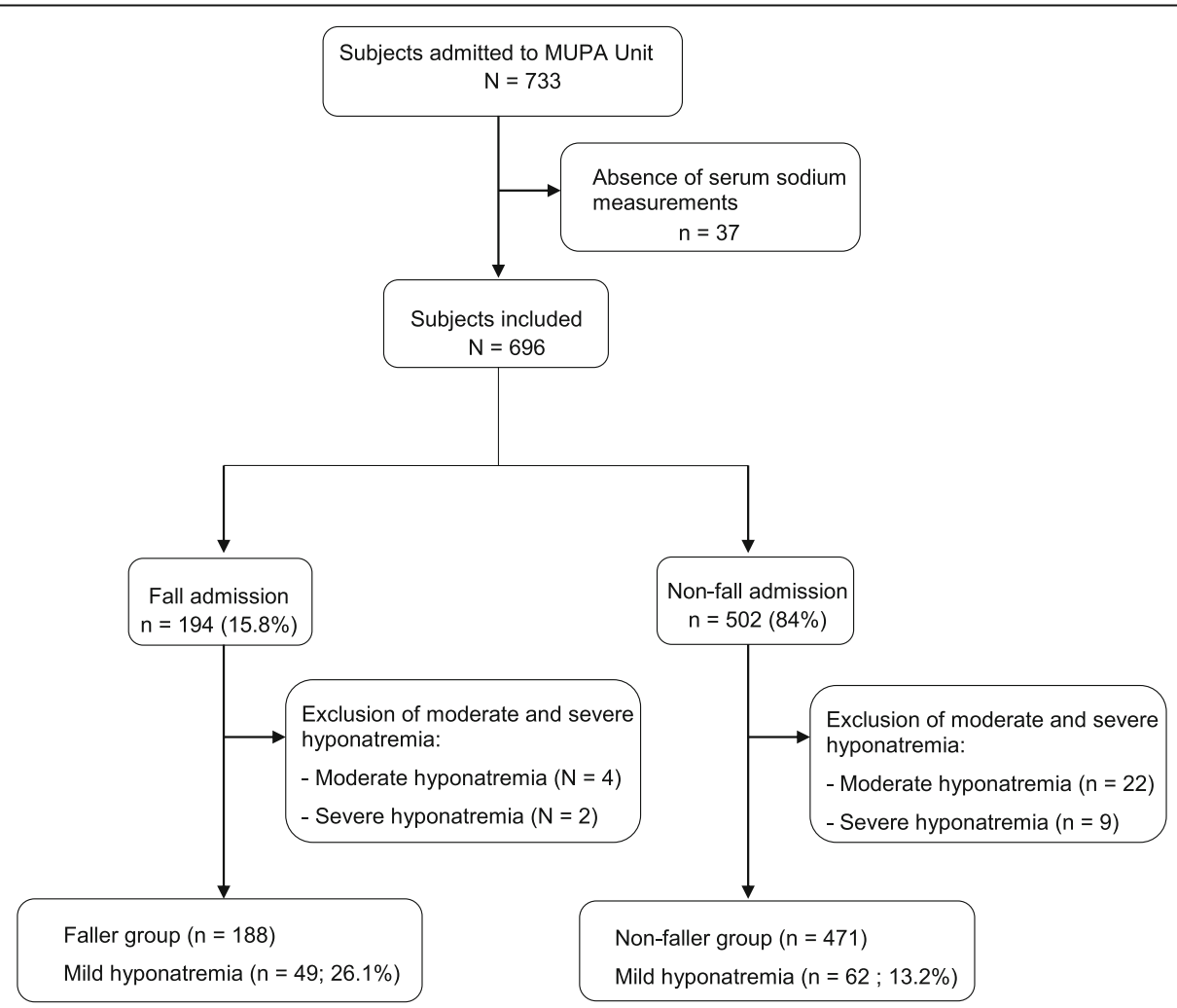

Fig. 1 Flowchart of patients admitted to the Emergency Geriatric Medicine Unit (MUPA) Unit from November 1, 2014 to March 31, 2015 in Limoges, France 
Table 1 Characteristics of patients admitted to the MUPA Unit

\begin{tabular}{|c|c|}
\hline Variables & $\begin{array}{l}\text { Patients } \\
(n=696)\end{array}$ \\
\hline Age $(y$, mean $\pm S D)$ & $86.1 \pm 5.6$ \\
\hline Female $n(\%)$ & $439(63.1)$ \\
\hline Frailty evaluation - SEGA (mean \pm SD) & $13.5 \pm 4$ \\
\hline Not particularly frail (SEGA $\leq 8), \mathrm{n}(\%)$ & $70(10.0)$ \\
\hline Frail $(8<$ SEGA $\leq 11), \mathrm{n}(\%)$ & $93(13.4)$ \\
\hline Very frail (SEGA > 11), n (\%) & $389(55.9)$ \\
\hline Unknown, n (\%) & $144(20.7)$ \\
\hline Autonomy evaluation - ADL (mean \pm SD) & $3.9 \pm 1.9$ \\
\hline Medication adherence - Morisky Test (mean \pm SD) & $3.5 \pm 1$ \\
\hline Emergency frailty score - ISAR (mean \pm SD) & $3.7 \pm 1.2$ \\
\hline Subjects not at risk (ISAR < 2), n (\%) & $13(1.9)$ \\
\hline Subjects at risk (ISAR $\geq 2), \mathrm{n}(\%)$ & $368(52.9)$ \\
\hline Unknown, n (\%) & $315(45.2)$ \\
\hline Geriatric Depression Scale - GDS (mean \pm SD) & $1.4 \pm 1.4$ \\
\hline No depression $(\mathrm{GDS}=0), n=146$ & $146(21.0)$ \\
\hline Depression $(G D S \geq 1), n=200$ & $200(28.7)$ \\
\hline Unknown, $n=350$ & $350(50.3)$ \\
\hline Number of diseases (mean \pm SD) & $4.3 \pm 2.6$ \\
\hline Number of drugs (mean $\pm S D$ ) & $6.4 \pm 3.1$ \\
\hline
\end{tabular}

\section{Prevalence of hyponatremia}

Hyponatremia $(<136 \mathrm{mEq} / \mathrm{L})$ was detected in 148 subjects and the prevalence was $21.30 \%$ (95\% confidence interval $[\mathrm{CI}]: 18.3-24.3 \%$, serum sodium concentration $=$ $130.8 \pm 6.3 \mathrm{mEq} / \mathrm{L})$. Of the 696 subjects, $15.9 \%(n=111$; 95\% CI: 13.2-18.6\%) had mild chronic hyponatremia, $3.7 \%$ ( $n=26$; 95\% CI: $2.3-5.1 \%$ ) had moderate hyponatremia, and $1.6 \%(\mathrm{n}=11 ; 95 \% \mathrm{CI}: 0.7-2.5 \%)$ had severe hyponatremia.

\section{Mild hyponatremia and its association with falls}

Table 2 compares baseline characteristics between patients admitted for a fall and those not admitted for a fall. Patients with moderate or severe hyponatremia ( $n=$ 37) were not included and data regarding general characteristics, geriatric assessments, comorbidities, and drugs at baseline were compared. Patients admitted to the MUPA Unit for a fall were significantly less dependent than those admitted for other reasons (ADL score: $4.6 \pm 1.5$ vs. $3.6 \pm 2.0$, respectively, $p<0.0001$ ); patients admitted for a fall were also less polypathological (number of diseases: $2.5 \pm 2.0$ vs. $3.2 \pm 2.1, p=0.0008$ ). The prevalence of mild hyponatremia was $13.2 \%$ (95\% CI: $10.1-16.3 \%)$ in patients without falls and $26.1 \%(95 \%$ CI: $19.8-32.4 \%)$.

in patients admitted for falls. Mild hyponatremia was significantly associated with falls $(\mathrm{P}<0.001)$ and the adjusted

Table 2 Characteristics of patients admitted to the MUPA Unit for falls

\begin{tabular}{|c|c|c|c|}
\hline Variables & $\begin{array}{l}\text { Falls } \\
(n=188)\end{array}$ & $\begin{array}{l}\text { Non-falls } \\
(n=471)\end{array}$ & $P$-value \\
\hline Age $(y$, mean $\pm S D)$ & $87 \pm 5.9$ & $87 \pm 5.6$ & 0.73 \\
\hline Female $n(\%)$ & $122(64.9)$ & $287(60.9)$ & 0.34 \\
\hline Frailty evaluation - SEGA (mean \pm SD) & $13.1 \pm 3.5$ & $13.7 \pm 4.2$ & 0.07 \\
\hline Little frail (SEGA $\leq 8), \mathrm{n}(\%)$ & $19(10.1)$ & $48(10.2)$ & 0.66 \\
\hline Frail $(8<$ SEGA $\leq 11)$, n (\%) & $30(16.0)$ & $57(12.1)$ & 0.26 \\
\hline Very Frail (SEGA > 11), n (\%) & $109(57.9)$ & $262(55.6)$ & 0.77 \\
\hline Unknown, n (\%) & $30(16.0)$ & $104(22.1)$ & 0.17 \\
\hline Autonomy evaluation - ADL (mean \pm SD) & $4.6 \pm 1.5$ & $3.6 \pm 2.0$ & $<0.0001$ \\
\hline Morisky (mean \pm SD) & $3.3 \pm 1.1$ & $3.6 \pm 1.1$ & 0.08 \\
\hline Emergency frailty score - ISAR (mean $\pm S D$ ) & $3.8 \pm 1.0$ & $3.8 \pm 1.2$ & 0.83 \\
\hline Subjects not at risk (ISAR < 2), n (\%) & $1(0.5)$ & $10(2.1)$ & 0.19 \\
\hline Subjects at risk (ISAR $\geq 2), \mathrm{n}(\%)$ & $112(59.6)$ & $237(50.3)$ & 0.25 \\
\hline Unknown, n (\%) & $75(39.9)$ & $224(47.6)$ & 0.27 \\
\hline Geriatric depression scale - GDS (mean \pm SD) & $1.2 \pm 1.4$ & $1.5 \pm 1.5$ & 0.18 \\
\hline No depression (GDS = 0), n (\%) & $51(27.1)$ & $87(18.5)$ & 0.05 \\
\hline Depression (GDS $\geq 1), \mathrm{n}(\%)$ & $56(29.8)$ & $132(28.0)$ & 0.78 \\
\hline Unknown, n (\%) & $81(43.1)$ & $252(53.5)$ & 0.27 \\
\hline Number of diseases (mean \pm SD) & $2.5 \pm 2.0$ & $3.2 \pm 2.1$ & 0.0008 \\
\hline Number of drugs (mean $\pm \mathrm{SD}$ ) & $6.0 \pm 3.0$ & $6.6 \pm 3.1$ & 0.05 \\
\hline
\end{tabular}

Student's $t$ tests were used for comparisons of quantitative variables and Fisher's exact tests were used for comparisons of qualitative variables between groups 
odds ratio (OR) was 3.02 (95\% CI: 1.84-4.96). The association between mild hyponatremia and falls remained significant after controlling for covariates (Table 3).

\section{Discussion}

\section{Main results}

The present population of patients admitted to the MUPA Unit was very frail and polypathological and the prevalence of mild hyponatremia was $15.9 \%$ (95\% CI: 13.2-18.6\%). The rate of fall recurrence was higher in females with mild hyponatremia than in males; importantly, the females were older and frailer than the males. There was a significant association between mild hyponatremia and the risk of injurious falls (falls resulting in admission to the MUPA Unit) but there were no significant associations among the risk of readmission for injurious fall, mortality, and level of natremia.

\section{Study strengths}

The present study is the first to demonstrate a link between mild hyponatremia and injurious falls among patients admitted to the MUPA Unit. Renneboog and al [18]. and Gunathilake and al [26]. also observed this association but investigated patients from a classic ED and living in the community but did not focus on geriatric assessments. The present study assessed the relationship between and falls among patients in the MUPA Unit and performed specific geriatric assessments. The relationship between natremia and falls is very interesting, particularly in the context of patients from a MUPA Unit, because mild hyponatremia is highly prevalent and these patients have a greater risk of falling. The present study is the first to investigate this particular relationship and, notably, revealed a significant difference between males and females with respect to the link between mild hyponatremia and risk of falls. Females admitted to the MUPA Unit were older and more dependent than the males, which may explain why their risk of falls was higher. These results demonstrate the necessity for the implementation of falls prevention strategies in the ED.

\section{Study limitations}

The present study was limited in that it focused on serum sodium concentrations obtained during the first blood test on arrival at the MUPA Unit. Thus, it was not possible to determine if the hyponatremia was acute or chronic because ofthe absence of longitudinal data. So, we concluded that "mild hyponatremia" was associated with falls in older adults admitted to the MUPA Unit. Further prospective and longitudinal studies of this relationship should be conducted. Additionally, the present study population was highly selective, in that the patients were admitted to the MUPA Unit for non-vital emergencies and the study focused only on geriatric assessments.

\section{Study context and implications}

The prevalence of hyponatremia in the present study (21.3\%) was slightly higher than that reported by previous studies. For example, Upadhay et al. [7] reported a prevalence of $18 \%$. However, this study recruited patients admitted to the MUPA unit whereas the participants lived at home in the previous study. Hyponatremia is associated with the occurrence of geriatric disorders, such as attentional and postural disorders, leads to a significant increase in the risk of fractures, and may be a risk factor of osteoporosis [18, 27, 28]. Some studies have implicated hyponatremia, particularly mild chronic hyponatremia, in cognitive disorders and suggested that chronic hyponatremia could induce attention disorders [18].

Additionally, patients with mild chronic hyponatremia may be more likely to develop osteoporosis [27] and this disorder could increase the risk of a fracture [16, 29] and osteoporosis [30]. The present study observed an association between mild chronic hyponatremia and falls among patients in the MUPA Unit, whereas previous studies included patients from classic EDs [18, 31, 32] and home-based populations [17]. Ahamed et al. [33] observed the same association between hyponatremia and falls but reported that the risk of falls in patients with mild hyponatremia was similar to the risks in those with moderate to severe hyponatremia.

\section{Conclusion}

In conclusion, the present findings demonstrated that elderly patients admitted to the MUPA Unit, and who exhibited mild chronic hyponatremia during the first blood test following arrival, had a higher risk of falling. Mild chronic hyponatremia could be considered a risk factor for falls and, thus, determination of sodium levels in ED assessments might be an important component of strategies for preventing injurious falls in the elderly. Nonetheless, the present findings of an association between mild chronic hyponatremia and falls should be confirmed by longitudinal and prospective studies.

Table 3 Prevalence rates of mild hyponatremia in patients admitted for falls and control subjects

\begin{tabular}{lllllll}
\hline Variable & $\begin{array}{l}\text { Patients } \\
(n=188)\end{array}$ & $\begin{array}{l}\text { Controls } \\
(n=471)\end{array}$ & Unadjusted & & Adjusted \\
& Percent (number) & & OR & $P$-value & OR & $P$-value \\
\hline Mild hyponatremia & $26.1(49)$ & $13.2(62)$ & $2.33(1.53-3.55)$ & 0.001 & $3.02(1.84-4.96)$ & 0.001 \\
\hline
\end{tabular}

Adjusted for age, sex, frailty status, functional autonomy, cognitive and depression status, number of drugs, and comorbidity index 


\section{Abbreviations}

ADL: Activity of Daily Living; CGA: Comprehensive Geriatric Assessment; Cl: Confidence Interval; ED: Emergency Department; GDS: Geriatric Depression Scale; MUPA: Médecine d'Urgence de la Personne Agée; OR: Odd Ratio; SEGA: Short Emergency Geriatric Assessment

\section{Acknowledgements}

This research was conducted with "La Chaire d'Excellence Académique E-santé, bien vieillir et autonomie" de la Fondation Partenariale de L'Université de Limoges.

\section{Authors' contributions}

SB drafted the manuscript. CG and TD read and revised the manuscript. CB helped perform statistical analysis. TM, PK, MC collected data. AT participated in the design of the study methodology and helped draft the manuscript. All authors read and approved the final manuscript.

\section{Funding}

No funding was obtained for this study.

\section{Availability of data and materials}

the dataset is not available but can be requested from the corresponding author.

\section{Ethics approval and consent to participate}

Written informed consent was obtained from all participants and Ethical approval for this study was obtained from the local ethics committee "Comité d'éthique".

\section{Consent for publication}

Not Applicable.

\section{Competing interests}

The authors declare that they have no competing interests.

\section{Author details}

'EA 6310 HAVAE Handicap Activité Vieillissement Autonomie Environnement, Université de Limoges, F-8705 Limoges, France. ${ }^{2}$ Unité de Recherche Clinique et Innovation (URCI) en Gérontologie (Axe Silver économie, e-santé et Télémédecine), Pôle HU Gérontologie Clinique, CHU de Limoges, 2 Avenue Martin-Luther King, 87042 Limoges, France. ${ }^{3} \mathrm{CHU}$ de Limoges, Pôle HU Gérontologie Clinique, 2 Avenue Martin-Luther King, F-87042 Limoges, France. ${ }^{4}$ Unité de Médecine d'Urgence de la Personne Âgée, Pôle Gérontologie Clinique, Centre Hospitalier Universitaire de Limoges, 2 Avenue Martin-Luther King, F-87042 Limoges, France. ${ }^{5}$ Geriatric Medicine, University of Limoges CHU Limoges, IFR 145 GEIST, EA 6310 HAVAE (Handicap Activité Vieillissement Autonomie et Environnement), F-87025 Limoges, France.

\section{Received: 15 June 2019 Accepted: 13 September 2019}

Published online: 15 October 2019

\section{References}

1. Tinetti ME, Speechley M. Prevention of falls among the elderly. N Engl J Med. 1989;320(16):1055-9.

2. Tinetti ME, Speechley M, Ginter SF. Risk factors for falls among elderly persons living in the community. N Engl J Med. 1988;319(26):1701-7.

3. Sterling DA, O'Connor JA, Bonadies J. Geriatric falls: injury severity is high and disproportionate to mechanism. J Trauma. 2001:50(1):116-9.

4. Suzuki M, Yamada K, Takahashi H, Tsuchiya S. A study of falls among elderly living in the community. Nihon Kango Kagakkaishi. 1993;13(2):10-9.

5. Mosenthal AC, Livingston DH, Elcavage J, Merritt S, Stucker S. Falls: epidemiology and strategies for prevention. J Trauma. 1995;38(5):753-6.

6. Suzuki T. Epidemiology and implications of falling among the elderly. Nihon Ronen Igakkai Zasshi. 2003;40(2):85-94.

7. Upadhyay A, Jaber BL, Madias NE. Incidence and prevalence of hyponatremia. Am J Med. 2006;119(7 Suppl 1):S30-5.

8. Adrogue HJ, Madias NE. Hyponatremia. N Engl J Med. 2000;342(21):1581-9.

9. Ganguli A, Mascarenhas RC, Jamshed N, Tefera E, Veis JH. Hyponatremia: incidence, risk factors, and consequences in the elderly in a home-based primary care program. Clin Nephrol. 2015;84(2):75-85.
10. Hawkins RC. Age and gender as risk factors for hyponatremia and hypernatremia. Clin Chim Acta. 2003;337(1-2):169-72.

11. Siregar $P$. The risk of hyponatremia in the elderly compared with younger in the hospital inpatient and outpatient. Acta Med Indones. 2011;43(3):158-61.

12. Soiza RL, Talbot HS. Management of hyponatraemia in older people: old threats and new opportunities. Ther Adv Drug Saf. 2011;2(1):9-17.

13. Shapiro DS, Sonnenblick M, Galperin I, Melkonyan L, Munter G. Severe hyponatraemia in elderly hospitalized patients: prevalence, aetiology and outcome. Intern Med J. 2010;40(8):574-80.

14. Arieff Al, Llach F, Massry SG. Neurological manifestations and morbidity of hyponatremia: correlation with brain water and electrolytes. Medicine (Baltimore). 1976;55(2):121-9.

15. Decaux G. Is asymptomatic hyponatremia really asymptomatic? Am J Med. 2006;119(7 Suppl 1):S79-82.

16. Gankam Kengne F, Andres C, Sattar L, Melot C, Decaux G. Mild hyponatremia and risk of fracture in the ambulatory elderly. QJM. 2008; 101(7):583-8.

17. Hoorn EJ, Rivadeneira F, van Meurs JB, Ziere G, Stricker BH, Hofman A, Pols HA, Zietse $\mathrm{R}$, Uitterlinden AG, Zillikens MC. Mild hyponatremia as a risk factor for fractures: the Rotterdam study. J Bone Miner Res. 2011:26(8):1822-8.

18. Renneboog B, Musch W, Vandemergel X, Manto MU, Decaux G. Mild chronic hyponatremia is associated with falls, unsteadiness, and attention deficits. Am J Med. 2006;119(1):71 e71-78.

19. Leveille SG, Kiel DP, Jones RN, Roman A, Hannan MT, Sorond FA, Kang HG, Samelson EJ, Gagnon M, Freeman M, et al. The MOBILIZE Boston study: design and methods of a prospective cohort study of novel risk factors for falls in an older population. BMC Geriatr. 2008:8:16.

20. Gibson MJ, Andres RO, Isaacs B, Radebaugh T, Wormpetersen J. The prevention of falls in later life - a report of the Kellogg-international-workgroup on the prevention of falls by the elderly. Dan Med Bull. 1987;34:1-24.

21. Schoevaerdts D, Biettlot S, Malhomme B, Rézette C, Gillet J, Vanpee D, Cornette $P$, Swine $C$. Identification précoce du profil gériatrique en salle d'urgences : présentation de la grille SEGA. La revue de gériatrie. 2004; 29(3):169-78.

22. Katz S. Assessing self-maintenance: activities of daily living, mobility, and instrumental activities of daily living. J Am Geriatr Soc. 1983;31(12):721-7.

23. Morisky DE, Green LW, Levine DM. Concurrent and predictive validity of a selfreported measure of medication adherence. Med Care. 1986;24(1):67-74.

24. McCusker J, Bellavance F, Cardin S, Trepanier S, Verdon J, Ardman O. Detection of older people at increased risk of adverse health outcomes after an emergency visit: the ISAR screening tool. J Am Geriatr Soc. 1999; 47(10):1229-37.

25. Yesavage JA, Brink TL, Rose TL, Lum O, Huang V, Adey M, Leirer VO. Development and validation of a geriatric depression screening scale: a preliminary report. J Psychiatr Res. 1982;17(1):37-49.

26. Hosmer DW, Hosmer T, Le Cessie S, Lemeshow S. A comparison of goodnessof-fit tests for the logistic regression model. Stat Med. 1997;16(9):965-80.

27. Verbalis JG, Barsony J, Sugimura Y, Tian Y, Adams DJ, Carter EA, Resnick HE. Hyponatremia-induced osteoporosis. J Bone Miner Res. 2010;25(3):554-63.

28. Verbalis JG, Gullans SR. Hyponatremia causes large sustained reductions in brain content of multiple organic osmolytes in rats. Brain Res. 1991;567(2):274-82.

29. Kinsella S, Moran S, Sullivan MO, Molloy MG, Eustace JA. Hyponatremia independent of osteoporosis is associated with fracture occurrence. Clin J Am Soc Nephrol. 2010;5(2):275-80.

30. Usala RL, Fernandez SJ, Mete M, Cowen L, Shara NM, Barsony J, Verbalis JG. Hyponatremia is associated with increased osteoporosis and bone fractures in a large US health system population. J Clin Endocrinol Metab. 2015; 100(8):3021-31.

31. Kuo SCH, Kuo PJ, Rau CS, Wu SC, Hsu SY, Hsieh CH. Hyponatremia Is Associated with Worse Outcomes from Fall Injuries in the Elderly. Int J Environ Res Public Health. 2017;14(5):460.

32. Rittenhouse KJ, To T, Rogers A, Wu D, Horst M, Edavettal M, Miller JA, Rogers FB. Hyponatremia as a fall predictor in a geriatric trauma population. Injury. 2015;46(1):119-23.

33. Ahamed S, Anpalahan M, Savvas S, Gibson S, Torres J, Janus E. Hyponatraemia in older medical patients: implications for falls and adverse outcomes of hospitalisation. Intern Med J. 2014;44(10):991-7.

\section{Publisher's Note}

Springer Nature remains neutral with regard to jurisdictional claims in published maps and institutional affiliations. 